\title{
Effect of diluents on high purity $\beta$-SiAIONs by mechanically activated combustion synthesis
}

\author{
Kazuhiko AOYAGI, Ramasamy SIVAKUMAR, ${ }^{\dagger}$ Xuemei YI, ${ }^{\dagger}$ Toshiyuki WATANABE and \\ Tomohiro AKIYAMA
}

Center for Advanced Research of Energy Conversion Materials, Hokkaido University, Sapporo 060-8628

\begin{abstract}
The influence of diluent addition on purities of $\beta-\mathrm{Si}_{5} \mathrm{AlON}_{7}$ powders synthesized by mechanically activated combustion synthesis (MA-CS) under a very low nitrogen atmosphere of $1 \mathrm{MPa}$ was investigated. The purity of $\beta-\mathrm{Si}_{5} \mathrm{AlON}_{7}$ powders increased with diluent concentrations in raw materials and had a maximum value of $91 \%$ when 40 mass $\%$ of diluents were added, a $25 \%$ more pure when compared to powders procured without diluents. In contrast, when diluents were included $50 \%$ or more, the combustion synthesis (CS) reaction did not occur due to reduced exothermic heat. The results also showed that the particle sizes of $\beta-\mathrm{Si}_{5} \mathrm{AlON}_{7}$ powders synthesized with 40 mass \% of diluents were only one-tenth when compared to powders synthesized without diluents.
\end{abstract}

(C)2009 The Ceramic Society of Japan. All rights reserved.

Key-words : Combustion synthesis, Mechanical activation, SiAION, Grain size, Diluents

[Received November 10, 2008; Accepted February 19, 2009]

\section{Introduction}

Since the discovery of $\beta$-SiAlONs $\left(\mathrm{Si}_{6-z} \mathrm{Al}_{z} \mathrm{O}_{z} \mathrm{~N}_{8-z}, 0<z \leq 4.2\right)$ in 1971, these materials are considered as of great technological importance due to their high toughness, heat resistance, and wear resistances. ${ }^{1)}$ They are formed due to simultaneous substitution of $\mathrm{Al}$ and $\mathrm{O}$ elements with $\mathrm{Si}$ and $\mathrm{N}$ in $\beta-\mathrm{Si}_{3} \mathrm{~N}_{4}$ and are applied in the promising areas of high temperature engineering ceramics, cutting tools and abrasive materials. ${ }^{2)}$ Though reaction sintering, an expensive process that involves much energy and time is a common method to synthesize $\beta$-SiAlONs, combustion synthesis (CS) is been practiced in recent years for ceramic powder syntheses due to procurement of high purity products despite impure starting materials with short processing time. Further, this costeffective synthesis requires only very low energy with an initial electrical ignition.

The CS of $\beta$-SiAlONs reported earlier usually needed $\mathrm{N}_{2}$ pressures ranging from $2 \mathrm{MPa}$ to a high pressure of $150 \mathrm{MPa}$ with ball milling of raw materials for long hours. ${ }^{3)}$ However, we succeeded in synthesizing $\beta$-SiAlON powders through mechanically activated coupled CS (MA-CS) without any diluent additions at a low $\mathrm{N}_{2}$ pressure of $1 \mathrm{MPa}$ for the first time. ${ }^{4-6)}$ The mechanical activation promotes the reactivity between the raw materials by providing frequent shocks using high energy planetary milling. In addition, the effect of raw material selection in obtaining high purity $\beta$-SiAlONs with diluents was also investigated. ${ }^{6)}$ Among the different raw material selection, the MA-CS of silicon, aluminum and silica raw materials showed the least pure $\beta$ $\operatorname{SiAlON}(z=1)$ products of $66 \%$ purity along with un-reacted $\mathrm{Si}$ as impurities. The presence of un-reacted Si was due to the melting of $\mathrm{Si}$ as the adiabatic/combustion temperature during reaction

\footnotetext{
Corresponding author: R. Sivakumar; E-mail: s.ramasamy1@ csuohio.edu

* Present address: Department of Chemical and Bio-medical Engineering, Cleveland State University, Cleveland OH 44070, USA
}

$(2300 \mathrm{~K})$ was much more than the melting point of $\mathrm{Si}(1687 \mathrm{~K}){ }^{4)}$ To bring down the combustion temperature as well as to slow down the speed of combustion front during reaction, diluents such as $\alpha / \beta-\mathrm{Si}_{3} \mathrm{~N}_{4}{ }^{7,8)}$ are used for better conversion of reactants and increase the purity of $\beta$-SiAlON products.

This work aims a systematic study to find the effect of diluent on purity of synthesized powders using various proportions of diluent in MA-CS of $\beta$-SiAlON $(z=1)$.

\section{Experimental}

Starting materials in this study were Si (Soekawa Chemicals Co., Ltd., Tokyo, Japan, 98\% purity, 1-2 $\mu \mathrm{m}$ ), Al (Kojundo Chemical Laboratory Co., Ltd., Saitama, Japan, 99.9\% purity, $3 \mu \mathrm{m}$ ), $\mathrm{SiO}_{2}$ (Kojundo Chemical Laboratory Co., Ltd., Saitama, Japan, $99.9 \%$ purity, $0.8 \mu \mathrm{m}$ ), and diluent of commercially available $\beta$-SiAlON $(z=1)$ (ISMAN J Corporation, Kawasaki, Japan, $0.5 \mu \mathrm{m}$ ). As comparative experiments, pre-synthesized $\beta$ $\mathrm{SiAlON}^{4), 6)}$ of $z=1(3.2 \mu \mathrm{m})$ was added as diluents to raw materials instead of commercially available ones. For simplicity, hereafter diluents used in this study of pre-synthesized $\beta$ SiAlON are expressed as $S_{\mathrm{p}}$ and the commercially available as $S_{\mathrm{c}}$. Raw material mixtures with various diluent percents $\left(S_{\mathrm{p}}\right.$ and $S_{\mathrm{c}}$ ) ranging from 10 to 60 mass $\%$ were considered for CS in this study. The reaction for $\beta$-SiAlON formation is given as:

$$
\begin{aligned}
& 9(1-x) \mathrm{Si}+2(1-x) \mathrm{Al}+(1-x) \mathrm{SiO}_{2}+ \\
& \quad 7(1-x) \mathrm{N}_{2}+x \mathrm{Si}_{5} \mathrm{AlON}_{7} \text { (diluent) } \rightarrow 2 \mathrm{Si}_{5} \mathrm{AlON}_{7}
\end{aligned}
$$

where, $x$ represents the mass ratio of diluent added. The measured raw materials were planetary milled to $18 \mathrm{~min}$. followed by $\mathrm{CS}$ at $1 \mathrm{MPa} \mathrm{N}_{2}$ pressure. ${ }^{4)}$ After CS, the phases were analyzed by an X-ray analyzer (Mini Flex, Rigaku Corporation, Tokyo, Japan). The morphology of the reaction products were examined by SEM (FE-SEM JSM-7000F, JOEL Ltd., Tokyo, Japan) and the average particle size of each product obtained from different diluent content was measured by laser diffraction based particle size analyzer (Partica LA-950, HORIBA, Ltd., 
Kyoto, Japan).

\section{Results and discussion}

The pre-synthesis of $S_{\mathrm{p}}$ for inclusion in raw materials as diluents was performed similar to our previous works ${ }^{4), 6}$ and the purity of SiAlONs were measured with respect to SiAlON contents in the synthesized powders. The pre-synthesized product had a purity/SiAlON content of $66 \%$ and rest being the unreacted $\mathrm{Si}$ as by-product. In our studies, ${ }^{4)-6)}$ the relative $\beta$ $\mathrm{SiAlON}$ content are calculated on the basis of X-ray diffraction peak intensities by following ratio $\beta$-SiAlON $/(\beta$-SiAlON $+\mathrm{Si})$ considering (111) and (220) diffraction peaks of Si and the (020) and (120) diffraction peaks of $\beta$-SiAlON. Xu et al. calculated $\beta$ SiAlON contents in the similar fashion, where $\beta$-SiAlON and $\beta$ $\mathrm{Si}_{3} \mathrm{~N}_{4}$ were detected in their studies. ${ }^{9)}$

Figure 1(i) shows the variation of sialon content with respect to the amount of diluents added in the raw materials. From the figure, it can be seen that the purity of SiAlON increased with the diluent concentration and had a maximum value of $91 \%$ when 40 mass $\% S_{\mathrm{p}}$ were added to the raw materials when compared to $66 \%$ purity with no diluents. No remarkable change in the SiAlON content or purity was observed in the product when 40 mass $\% S_{c}$ was added, which had also an increased purity of $90 \%$ after CS. On contrary, when the diluent amounts was increased to 50 or 60 mass $\%$, there was no propagation in the reaction. This extinction of reaction is due to reduced exothermic heat produced during CS and can be explained by the adiabatic temperatures $\left(T_{\mathrm{ad}}\right)$ during the reaction. The $T_{\mathrm{ad}}$ can be calculated by the following equation:

$$
\int_{298}^{T_{\mathrm{ad}}}\left(\sum_{i} n_{i} C_{i \mathrm{p}}\right) \mathrm{d} T=-\Delta H_{\mathrm{r}}^{0}
$$

where $n_{i}$ expresses a stoichiometric number of a product $(i), C_{i \mathrm{p}}$ gives its molar heat capacity of the product and $\Delta H_{\mathrm{r}}^{0}$ is a standard enthalpy of reaction. ${ }^{4)}$ In this calculation, it is assumed that there was no heat loss from the container with raw material mixture during CS. As shown in Fig. 1(ii), there is a gradual decrease in

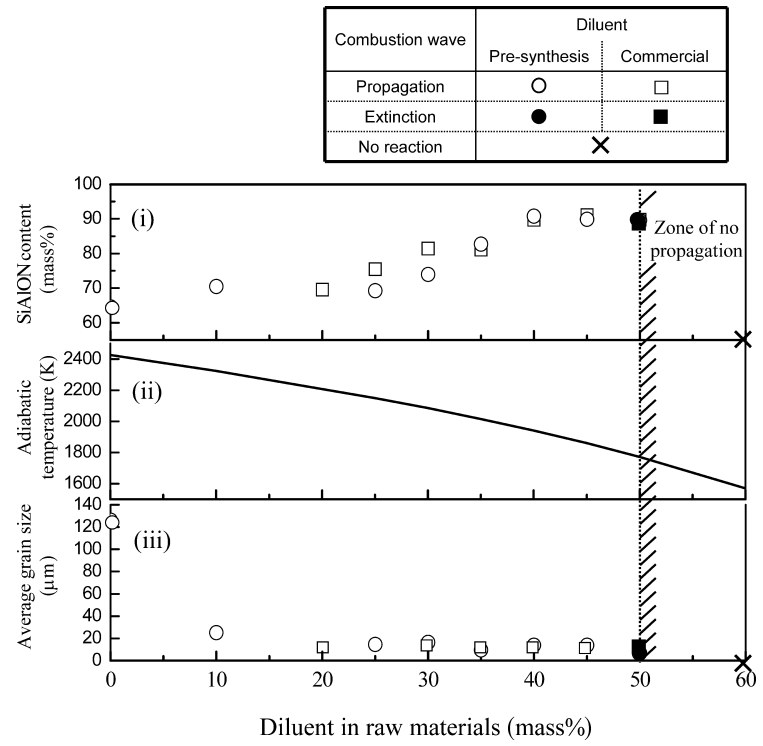

Fig. 1. Variation of (i) $\beta$-SiAlON contents in raw material mixture, (ii) adiabatic temperatures and (iii) average grain sizes of synthesized powders with respect to diluents percent (pre-synthesized and commercially available). the calculated $T_{\text {ad }}$ with the increase in diluent additions. The $T_{\text {ad }}$ was $1772 \mathrm{~K}$ and $1571 \mathrm{~K}$ for raw materials consisting of 50 and 60 mass \% diluents, respectively. Munir and Anseimi-Tamburini. ${ }^{10)}$ had established earlier that the combustion synthesis reaction will not self-sustain or propagate unless the $T_{\mathrm{ad}} \geq 1800 \mathrm{~K}$. From the experimental results, it was seen that when the diluent additions are increased to $50 \%$ or more, the combustion synthesis reactions did not self-sustain that has $T_{\text {ad }}$ less than or equal to $1800 \mathrm{~K}$, which agrees well with Munir and Anseimi-Tamburini. ${ }^{10}$ ) review.

Further, in our previous work $^{6)}$ it was proposed that a legitimate blend of moderate/threshold amounts of aluminum content in raw materials responsible for the combustion as well as a limited calorific value that controls a better conversion of reactants to products is required to obtain a prominent purity of $\beta$ SiAlONs. The thermo-chemical calculations were perfomed by software (HSC Chemistry Ver. 4, Finland). For $z=1$ SiAlONs (without diluents) of sialon content $66 \%$, the $\mathrm{Al}$ content and calculated calorific values were 0.15 mass $\%$ and $1.435 \mathrm{~kJ} / \mathrm{mol}$, respectively. On the other hand, with a different raw material selection without diluent ( $\mathrm{Si}, \mathrm{Al}$ and $\left.\mathrm{Al}_{2} \mathrm{O}_{3}\right)$ for $\beta$-SiAlON that possesed a $z$ value of 4 , the $\mathrm{Al}$ content and calorific values were $0.16 \mathrm{mass} \%$ and $0.92 \mathrm{~kJ} / \mathrm{mol}$ and had a increased sialon content of $88 \%$. A high calorific value will lead to high temperatures as well as increased combustion front velocity during synthesis, thereby reducing the purity of sialon products. ${ }^{6}$ In our present work, $z=1$ sialons were synthesized with various proportions of diluents and the purity of sialons are discussed with respect to the $\mathrm{Al}$ content in raw materials and calculated calorific values. Table 1 details the $\mathrm{Al}$ ratio and calorific values with the variation in diluent content in raw material mixture. From the table, it is clear that the calorific value decreases with the increase in diluent fractions as well as sialon content/purity in the synthesized product. A maximum purity of $91 \%$ was obtained for raw material mixture containing $40 \%$ of diluent addition. The corresponding $\mathrm{Al}$ content and calorific values of this high pure sialon were 0.15 mass $\%$ and $0.94 \mathrm{~kJ} / \mathrm{mol}$, which had close resemblance

Table 1. Aluminum Proportions in Raw Materials, Calculated Calorific Values and $\beta$-SiAlON Contents with Respect to $z$ Values and Diluent Contents

\begin{tabular}{ccccc}
\hline $\begin{array}{c}\text { SiAlON }^{\mathrm{a}} \text { values } \\
(\text { mass })\end{array}$ & $\begin{array}{c}\text { Al content } \\
\text { added } \\
(\text { mass\% })\end{array}$ & $\begin{array}{c}\text { Calculated } \\
\text { calorific } \\
\text { values } \\
(\mathrm{kJ} / \mathrm{mol})\end{array}$ & $\begin{array}{c}\text { SiAlON } \\
\text { content } \\
(\text { mass\% })\end{array}$ \\
\hline 1 & 0.15 & 0 & 1.435 & 66 \\
& 10 & 1.405 & 70 \\
& 25 & 1.171 & 69 \\
& 30 & 1.093 & 74 \\
& 35 & 1.015 & 83 \\
& 40 & 0.937 & 91 \\
& & 45 & 0.859 & 90 \\
& & 50 & 0.781 & 90 \\
& & 60 & 0.625 & $-{ }^{\mathrm{b}}$ \\
\hline $4^{\mathrm{c}}$ & 0.16 & 0 & 0.920 & 88 \\
\hline
\end{tabular}

${ }^{\mathrm{a}}\left(\mathrm{Si}_{6-z} \mathrm{Al}_{z} \mathrm{O}_{2} \mathrm{~N}_{8-z}\right)$

${ }^{\mathrm{b}}$ Reaction not propagated

${ }^{c}$ Ref. 6, Different raw material source $\left(\mathrm{Si}, \mathrm{Al}\right.$ and $\mathrm{Al}_{2} \mathrm{O}_{3}$ ) 

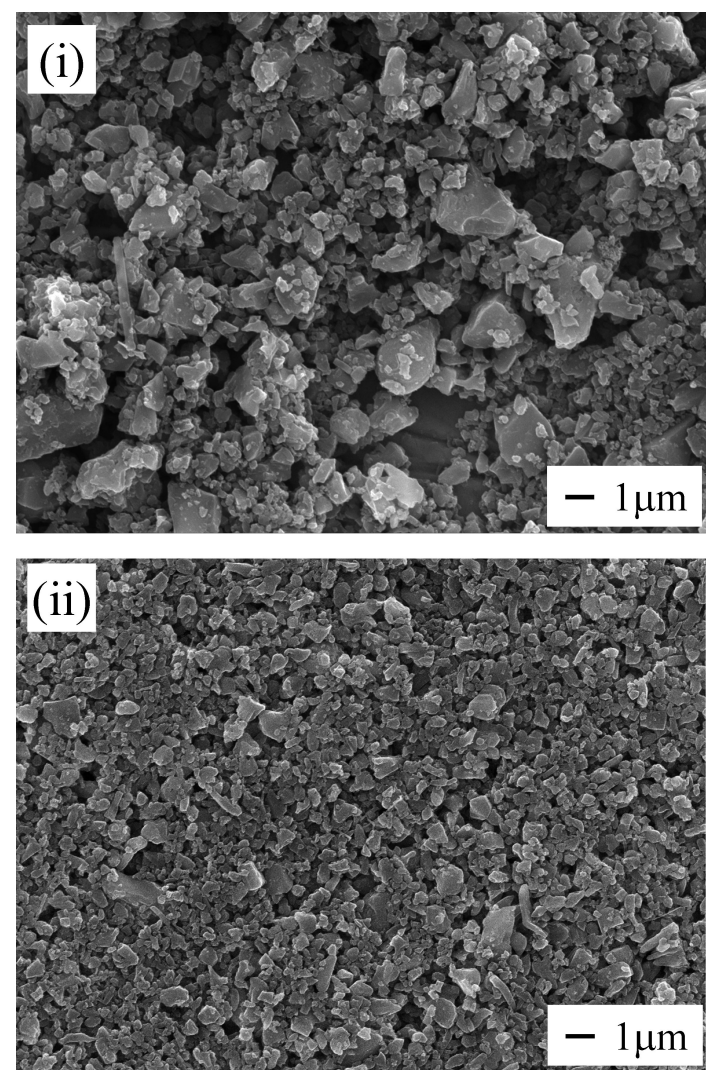

Fig. 2. SEM micrographs of combustion-synthesized $\beta-\mathrm{Si}_{5} \mathrm{AlON}_{7}$ with (i) no diluent and (ii) 40 mass $\%$ of pre-synthesized diluent $\left(S_{\mathrm{p}}\right)$.

to high pure sialon obtained from different raw material selection ( $\mathrm{Si}, \mathrm{Al}$ and $\mathrm{Al}_{2} \mathrm{O}_{3}$ ) without diluent, 0.16 mass $\%$ and $0.92 \mathrm{~kJ} / \mathrm{mol}$, respectively. Thus, it is validated that for successful propagation of $\beta$-SiAlONs with increased purity, a combination of moderate aluminum content in raw materials and a limited calorific value that controls a better conversion of reactants to products is a prerequisite.

Another notable feature of grain size reduction was found with the increase in diluent additions. Figure 1(iii) shows the variation of average grain size of sialon powders after synthesis with respect to diluent fractions in raw material mixtures. With no diluent addition in raw materials, the grain size was as high as $120 \mu \mathrm{m}$. An increase in diluent proportion to 10 mass $\%$ reduced the average particle size steeply to $20 \mu \mathrm{m}$. Further increase in diluents of 40 mass $\%$ still decreased the particle sizes of synthesized powders to $10 \mu \mathrm{m}$. It was also seen that there was no comparable difference in grain sizes with dependence of different diluents $S_{\mathrm{p}}$ and $S_{\mathrm{c}}$. Liu and coworkers ${ }^{11)}$ similarly found that the addition of $\alpha-\mathrm{Si}_{3} \mathrm{~N}_{4}$ diluents in $\mathrm{Yb} \alpha$-SiAlON combustion synthesis weakened the agglomeration, thus facilitating a better conversion of reactants to products. The $T_{\text {ad }}$ can be reasoned for decrease in grain sizes with diluent addition. For $z=1$ sialons without diluents, the calculated $T_{\text {ad }}$ is $2300 \mathrm{~K}$ during synthesis. At this high temperature, the $\mathrm{Si}$ in raw materials melts as its melting point is $1687 \mathrm{~K}$ and hardens to lump thereby preventing the further intrusion of nitrogen gas to convert the reactant to products. Hence, agglomerations of un-reacted $\mathrm{Si}$ were present as by-products. In contrast, with the increase in diluent concentration, the $T_{\text {ad }}$ decreased and slows down the combustion front velocity for better conversion to products in turn decreasing the particle agglomerations. Figure 2 shows the micrographs of synthesized $\beta$-SiAlON powders $(z=1)$ that had no diluent and that contains 40 mass $\%$ diluent $\left(S_{\mathrm{p}}\right)$ in the raw material mixture. From the figure, it is obvious that there is a significant decrease in the grain size of synthesized product when diluent is added to the raw materials.

\section{Conclusion}

The following are the conclusions drawn from the present work:

(i) Raw material mixtures with various proportions of presynthesized $\left(S_{\mathrm{p}}\right)$ and commercially available $\left(S_{\mathrm{c}}\right) \beta$-SiAlON $(z=1)$ diluents were successfully converted to high purity $\beta$-SiAlON $(z=$ $1)$ powders by MA-CS, when compared to $\beta$-SiAlONs synthesized without diluent additions.

(ii) The purity of the $\beta$-SiAlON product increased steadily with addition of diluents and a maximum purity of 91 mass\% was procured when $40 \%$ of diluents were added to raw material mixtures. There was no much influence on purity of synthesized powders with respect to the difference in $S_{\mathrm{p}}$ and $S_{\mathrm{c}}$ diluents.

(iii) When excessive diluents of $50 \%$ or more were added to raw material mixtures, the reaction did not propagate during CS due to weak exothermic heat. Thus, a desired amount of diluent is required for high purity of SiAlON product. In addition, it is validated that a legitimate blend of moderate/threshold amounts of aluminum content in raw material mixture as well as limited calorific value are necessary for acquiring high purity $\beta$ SiAlONs.

(iv) Diluents in the raw materials reduced the particle size of product a one-tenth of that when compared to products synthesized without diluents.

\section{References}

1) N. Calıs, S. R. Kushan, F. Kara and H. Mandal, J. Eur. Ceram. Soc., 24, 3387-3393 (2004).

2) T. Ekstrom and M. Nygren, J. Am. Ceram. Soc., 75[2], 259276 (1992)

3) K. L. Smirnov and I. P. Borovinskaya, Key Eng. Mater., 217, 159-164 (2002).

4) K. Aoyagi, T. Hiraki, R. Sivakumar, T. Watanabe and T. Akiyama, J. Am. Ceram. Soc., 90[2], 626-628 (2007).

5) K. Aoyagi, T. Hiraki, R. Sivakumar, T. Watanabe and T. Akiyama, J. Alloy. Compd., 441, 236-240 (2007).

6) R. Sivakumar, K. Aoyagi and T. Akiyama, J. Mater. Res., 22[10], 2863-2867 (2007).

7) J. Zeng, Y. Miyamoto and O. Yamada, J. Am. Ceram. Soc., 73[12], 3700-3702 (1990).

8) Y. Wu, H. Zhuang, F. Wu, D. Dollimore, B. Zhang, S. Chen and W. Li, J. Mater. Res., 13[1], 166-172 (1998).

9) X. Xu, T. Nishimura, N. Hirosaki, R. Xie, Y. Yamamoto and H. Tanaka, Nanotech., 16, 1569-1573 (2005).

10) Z. A. Munir and U. Anseimi-Tamburini, Mater. Sci. Rep., 3 , 277-365 (1989).

11) G. Liu, K. Chen, H. Zhou, X. Ning and J. M. F. Ferreira, J. Eur. Ceram. Soc., 25, 3361-3366 (2005). 